\title{
Importância da contabilidade gerencial na gestão e tomada de de- cisão: O município de Vassouras como estudo de caso
}

\author{
Importance of management accounting in decision-making: The Vassouras county as case study
}

Adriana T. D. C. Maia Lavinas.

Como citar esse artigo. Lavinas ATDCM. Importância da contabilidade gerencial na gestão e tomada de decisão: O município de Vassouras como estudo de caso. Revista Mosaico. 2013 Jul./Dez.; $04 \quad$ (2): 19-30.

\begin{abstract}
Resumo
Esse trabalho tem como objetivo demonstrar a importância da Contabilidade Gerencial para o processo de tomada de decisão e ampliação da capacidade de gestão nos Micro e Pequenos empreendimentos, além de identificar o conhecimento acerca da Contabilidade Gerencial, bem como sua utilização pelos administradores e gestores no Município de Vassouras - RJ. O estudo fundamenta-se em pesquisa exploratória e descritiva utilizando como abordagem metodológica entrevista através questionário fechado. Considerando-se que o contexto atual empresarial é determinado pelo dinamismo e incerteza, através de um mercado cada vez mais competitivo, o processo informacional passou a ser um diferencial para a permanência das empresas no mercado. A Contabilidade Gerencial contribui como instrumento eficaz voltado para o suprimento das necessidades gerenciais e apoio no processo decisório do empreendedor, através da geração de informação e conhecimento contribuindo para a sustentabilidade das Micro e Pequenas Empresas. Palavras-chave: Contabilidade Gerencial. Micro e Pequenas Empresas. Tomada de decisão. Gestão.
\end{abstract}

\begin{abstract}
This study aims to demonstrate the importance of management accounting for decision-making process and increase the management capacity in Micro and Small enterprises and identify the knowledge about the managerial accounting and its use by the Directors and Managers in the City of Vassouras - RJ. The study is based on exploratory and descriptive research using interviews as a methodological approach using closed questionnaire. Considering that the current context is determined by business dynamism and uncertainty, through an increasingly competitive market, the informational process has become a differentiator for the permanence of the firms. The Managerial Accounting contributes as an effective tool toward the supply of managerial needs and support decision-making process of the entrepreneur, by generating information and knowledge contributing to the sustainability of the Micro and Small Enterprises. Keywords: Managerial Accounting. Micro and Small Enterprises. Decision making. Management.
\end{abstract}

\section{Introdução}

O presente estudo busca contribuir para a reflexão sobre tema importante ao mundo dos negócios: a Contabilidade Gerencial como ferramenta de gestão e tomada de decisão para Micro e Pequenas Empresas (MPEs). A Contabilidade Gerencial pode desempenhar papel estratégico para a sustentabilidade dos empreendimentos por tratar-se de instrumento que amplia as informações necessárias ao processo decisório e gera vantagem competitiva, contribuindo para o enfraquecimento de mortalidade das Micro e Pequenas Empresas.

Para tal, optou-se por estabelecer investigação sobre os empreendimentos situados em Vassouras, cidade interiorana do Estado do Rio de Janeiro. Como ponto central e fio condutor deste trabalho, partiu-se da análise da realidade dos negócios locais a fim de verificar a relação dos empreendedores com esta importante ferramenta gerencial. Pretendemos responder ao longo deste trabalho, se os empreendedores conhecem e fazem uso das ferramentas gerenciais propiciadas pela Contabilidade Gerencial. Pretendeu-se verificar ainda se esses empreendedores estão restritos, em suas relações com seus Contadores, apenas no atendimento às exigências fiscais ou se os relatórios contábeis são utilizados também para fins de tomada de decisão.

Buscou-se compreender se as causas de insustentabilidade dos negócios locais estão aliadas a falta de conhecimento de natureza gerencial. Dessa forma, a Contabilidade Gerencial agrega valor aos empreendimentos fornecendo a base necessária 
para aperfeiçoar o processo decisório por meio das informações geradas.

O estudo se justifica no sentido de apresentar a Contabilidade Gerencial em seu papel potencial de minimizar a mortalidade de Micro e Pequenas Empresas. A bibliografia sobre a mortalidade de empresas é farta em apresentar como um dos principais motivos de insolvência dos negócios as falhas gerenciais. $\mathrm{O}$ insucesso das iniciativas empreendedoras podem trazer resultados irreversíveis, visto que a descrença no investimento em novos negócios gera desestímulo ao empreendedor diretamente envolvido e a toda sua rede de contatos.

Os negócios insustentáveis geram receio em relação a novos investimentos, o que pode deslocar capitais para outras atividades econômicas, como especulação imobiliária, aplicação em fundos de renda fixa ou ainda caderneta de poupança. Como resultado, a menor circulação de capitais e os desestímulos a novos empreendimentos podem levar a elevação das taxas de desemprego, arrastando a região a um risco de colapso em toda cadeia produtiva.

Diante do exposto, nota-se a necessidade de percepção por parte dos empreendedores sobre $\mathrm{o}$ instrumento eficiente da Contabilidade Gerencial como benefício potencial para o sucesso dos empreendimentos, propiciando um maior conhecimento de informação e fundamentando políticas e ações que propiciem melhor êxito na gestão empresarial. Adicionalmente assinalamos ser relevante o estudo do tema para o desenvolvimento de mecanismos para se criar um diferencial competitivo para os empreendimentos locais.

\section{Informações socioeconômicas município de Vassouras}

Para a composição da presente pesquisa foram utilizadas informações sociais, demográficas e econômicas do IBGE (Instituto Brasileiro de Geografia e Estatísticas de 2010) e do SEBRAE (2011).

O município de Vassouras encontra-se situado na Região Centro-Sul Fluminense, que é composta pelos municípios de Areal, Comendador Levy Gasparian, Engenheiro Paulo de Frontin, Mendes, Miguel Pereira, Paraíba do Sul, Paty do Alferes, Sapucaia e Três Rios. O município, que conta com uma economia baseada em indústrias, comércio, agronegócios, serviços e turismo, é constituído de três distritos: Andrade Pinto, São Sebastião dos Ferreiros e Sebastião de Lacerda.

Vassouras conta com uma população de 34.410 (trinta e quatro mil e quatrocentos e dez) habitantes, correspondentes a $12,64 \%$ do total da população da Região Centro-Sul Fluminense do Estado do Rio de Janeiro. Possui uma área de unidade territorial de 538, $134 \mathrm{~km}^{2}$ e densidade demográfica de $63,94 \mathrm{hab} / \mathrm{km}^{2}$.

O PIB (Produto Interno Bruto) do município corresponde a $\mathrm{R} \$ 320.449,00$, o que representa $10,10 \%$ do PIB da Região Centro-Sul Fluminense. Com relação ao raqueamento regional, o município de Vassouras ocupa a terceira posição, estando na primeira posição o município de Três Rios, seguido por Paraíba do Sul. - O setor que mais contribui para o PIB do município é o de serviços, seguido pelo setor industrial, conforme mostrado no Gráfico 1.

Gráfico 1. Participação dos Setores no PIB do Município a preços correntes.

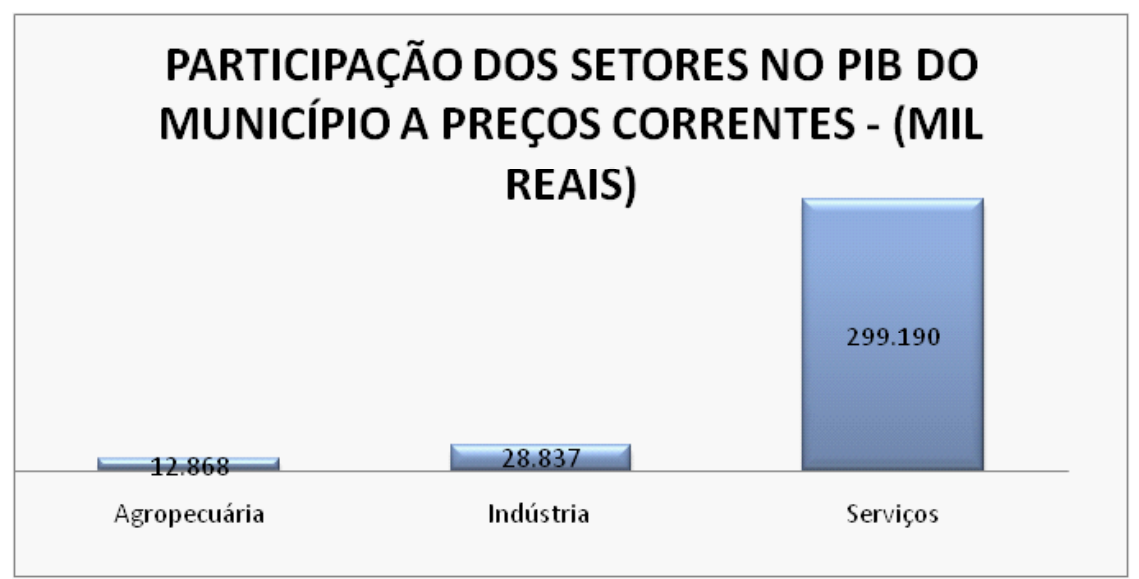

Fonte. IBGE (2010)

1 Cf. ANTHONY A. ATKINSON, RAJIV D. BANKER, ROBERT S. KAPLAN, S. MARK YOUNG - Contabilidade Gerencial. $2^{\mathrm{a}}$ ed. Atlas, 2008. Cf. BES, Fernando de Trías. O livro negro do empre-

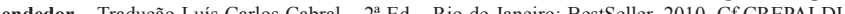
Silvio Aprecido. Teria e Pratica da Contabilidade Gerencil $2^{2}$ cl Ats, 2008. Cf. DOLABELA e um plano de negócios: como nasce o empreendedor e se cria uma empresa. São Paulo: Cultura, 1999.
Vassouras conta com um universo de 7.449 domicílios, sendo 2.141 (28,7\%) de famílias pertencentes à Classe Econômica "C1", definidas como aquelas que possuem renda familiar mensal em torno de $\mathrm{R} \$ 1.400,00$. O Gráfico 2 apresenta a distribuição dos domicílios segundo a classe econômica. 
Gráfico 2. Números de Domicílios/ Classes Econômicas do Município de Vassouras.

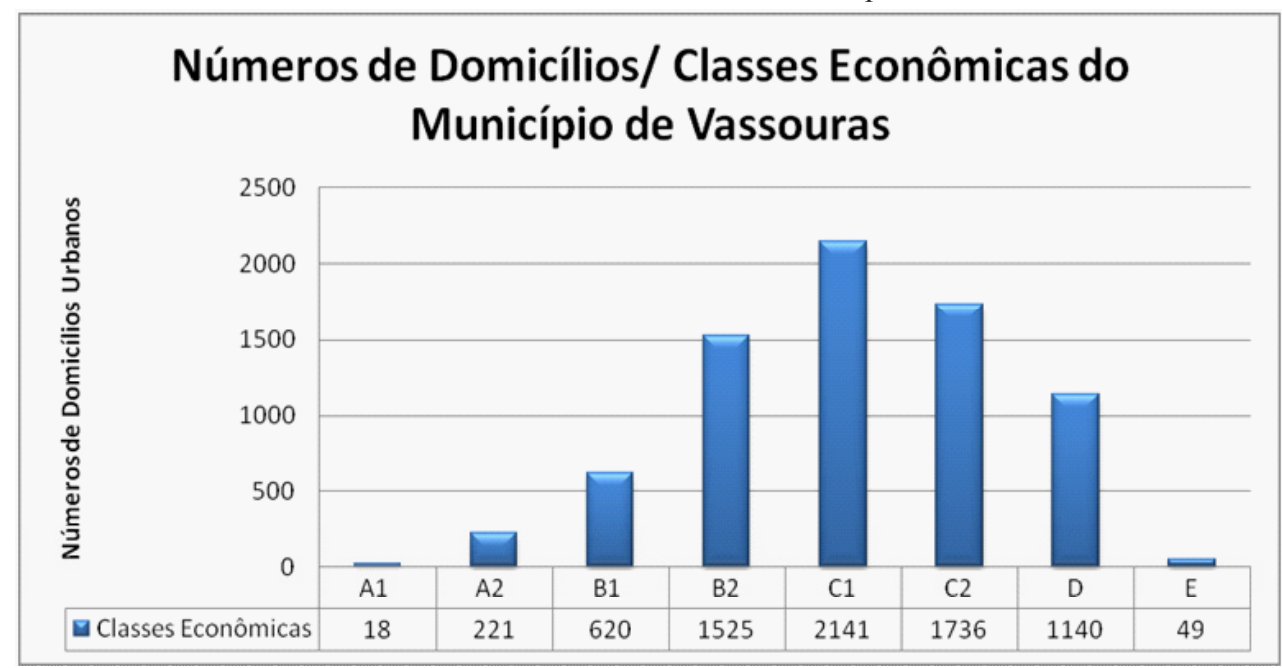

Fonte. IBGE(2010)

Observa-se no Gráfico 3 que apesar da classe "C1" ser a mais representativa no município, fica em segundo lugar no total de consumo urbano, representando
$22,63 \%$ do total de consumo, enquanto que a classe "B2" é a mais significativa em termos de consumo urbano, representando $27,25 \%$ do consumo total.

Gráfico 3. Consumo Familiar De Vassouras por Classe Econômica, segundo categorias de consumo em $\mathrm{R} \$ / \mathrm{ANO}$.

\section{CONSUMO FAMILIAR DE VASSOURAS POR CLASSE ECONÔMICA, SEGUNDO CATEGORIAS DE CONSUMO - EM R\$IANO}

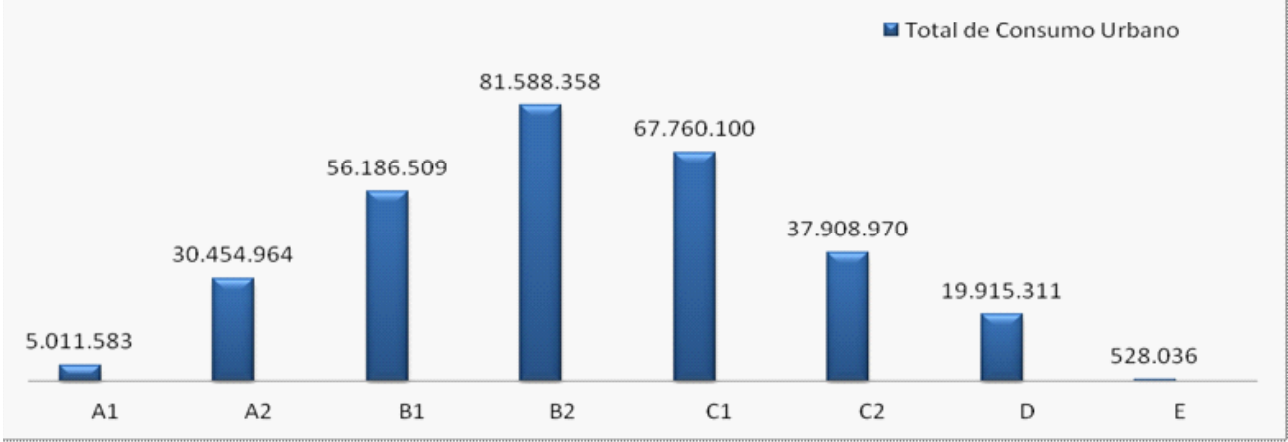

Fonte. IBGE(2010).

A população é, em sua maior parte, urbana e apresenta uma participação feminina superior à masculina em uma proporção de 91 homens para cada 100 mulheres.

Para melhor visualização de como a população se divide, a Tabela 1 mostra a distribuição segundo o IBGE.

Tabela 1. População Urbana e Rural

\begin{tabular}{cc}
\hline \multicolumn{2}{c}{ População Urbana e Rural } \\
\hline População Residente Urbana & 23.199 \\
\hline População Residente Rural & 11.211 \\
Homens & 16.391 \\
Mulheres & 18.019 \\
\hline Homens na área Urbana & 10.823 \\
Mulheres na área Urbana & 12.376 \\
Homens na área Rural & 5.568 \\
\hline Mulheres na área Rural & 5.643 \\
\hline
\end{tabular}

Fonte. IBGE, Censo Demográfico 2010.
Na Tabela 2 pode-se observar que a maioria da população encontra-se na faixa etária entre 30 e 49 anos, seguida pela faixa de 50 ou mais anos.

Tabela 2. População por Faixas Etárias

\begin{tabular}{cc}
\hline \multicolumn{2}{c}{ População Urbana e Rural } \\
\hline $0-4$ anos & 2071 Pessoas \\
$5-9$ anos & 2460 Pessoas \\
$10-14$ anos & 2896 Pessoas \\
$15-19$ anos & 2857 Pessoas \\
$20-29$ anos & 5834 Pessoas \\
$30-49$ anos & 9726 Pessoas \\
$50+$ anos & 8566 Pessoas \\
\hline
\end{tabular}

Fonte. IBGE, Censo Demográfico 2010.

Observando-se a tabela, é possível notar que a população de Vassouras está envelhecendo consideravelmente. Esses dados podem representar uma 
transformação (em muito pouco tempo) na estrutura populacional, o que acarretará profundas repercussões econômicas, políticas e sociais, merecendo uma atenção especial do poder público para a implantação de políticas públicas voltadas para a terceira idade no município.

É importante destacar que tais alteraçõespoderão provocar mudanças no estilo de vida e consumo, algo a que os empreendedores locais devem ter atenção. Segundo pesquisa da INFOMONEY (2001), a maior parte da população idosa tem alguma fonte de renda própria (92\%), tanto os idosos homens (97\%), como as idosas $(87 \%)$, e contribui para a renda familiar $(88 \%$, respectivamente $95 \%$ e $83 \%$ ). O estudo mostrou que $69 \%$ das pessoas na terceira idade são as principais responsáveis pelo orçamento familiar. Quanto menor a classe econômica pertencente maior o percentual, sendo na classe D $77 \%$ e na classe C $68 \%$.

\section{O Turismo}

Vassouras é conhecida como "Terra dos Barões", pela profusão de títulos nobiliárquicos que receberam parte de seus senhores rurais ao longo da segunda metade do século XIX. Conta com peculiar referência histórica somada a existência de um dos maiores conjuntos integrados de Bens Tombados como Patrimônio Material da Nação pelo Instituto do Patrimônio Histórico Nacional (IPHAN), fazendo com que se destaque no campo turístico.

O Município conta com o "Festival Vale do Café", que em fevereiro de 2010 recebeu o Prêmio de Cultura do Estado do Rio de Janeiro na categoria Empreendedorismo, promovido pela Secretaria de Estado de Cultura do Rio de Janeiro. A premiação foi concebida a partir da junção de três prêmios - Golfinho de Ouro, Estácio de Sá e Governo do Rio de Janeiro, onde através dela, o Governo do Estado reverencia e difunde a diversidade, a qualidade e a riqueza da criação cultural do Rio de Janeiro. O Festival é viabilizado com base na Lei Rouanet e na Lei Estadual de Incentivo à Cultura do Rio de Janeiro. Evento que ocorre desde 2003 e contribui expressivamente com o cenário econômico da região.

O município tem riquezas culturais que envolvem também o campo imaterial representado pelos grupos culturais de manifestações populares como a Capoeira e Jongo.

O turismo tem expressividade por ser uma atividade que demanda muita mão de obra, gerando empregos diretos e indiretos. $\mathrm{O}$ efeito provocado pelo gasto dos turistas, em bens e serviços consumidos na localidade, aumenta a geração de novos empregos e de renda.

O turismo pode ser avaliado como um meio onde o capital gerado permaneça na região, para ser reinserido na economia local. Parte do que os turistas gastam em hotéis, restaurantes e lazer são destinados, entre outras possibilidades, aos salários dos empregados, que por sua vez pagam aluguéis, transporte, educação, compras, causando um efeito multiplicador. Segundo o analista Frank M. Go (1994 apud Trigo, 1998, p. 16) "o turismo pode atuar como peça importante em um contexto maior de planejamento ambiental e auxiliar a qualidade de vida, especialmente no nível local".

Outro aspecto não menos importante, parte da compreensãoqueaconscientizaçãoporpartedapopulação das ações por eles realizadas - e sensibilizando-as em todos os aspectos, pois a atividade turística só pode ser desenvolvida de maneira sustentável - tras benefícios para a localidade em todos seus setores, quando o planejamento é feito dentro das realidades locais e gerido com participação das comunidades, envolvendo e vinculando a comunidade ao máximo aos projetos; são os moradores do local que deverão ter a chance de encontrar as soluções e caminhos comuns delineando as diretrizes para o desenvolvimento do turismo, são eles que podem garantir os serviços necessários à indústria do turismo, a qual, desta forma atuará de forma mais eficiente e eficaz.

\section{Desenvolvimento Industrial}

No que toca a questão de desenvolvimento industrial o município conseguiu se inserir no projeto lei $2595 / 09$ que reduziu o imposto do ICMS para $2 \%$ antes o imposto cobrado para a inserção de empresas em Vassouras era de 19\%.A redução pode possibilitar grande incremento a atração de empreendimentos industriais, estimulando a economia local e aquecendo a geração de empregos. Pode, portanto, causar efeito positivo para a região em todos os setores de negócios e elevar a propensão de investimentos e diversificação da cadeia produtiva, atraindo segmentos econômicos considerados relevantes para incentivo ao desenvolvimento local como a infraestrutura, o desenvolvimento do capital humano e amortecimento do desemprego.

Segundo dados da Prefeitura Municipal de Vassouras o município possui no Bairro Toca dos Leões um parque industrial empresa Toque A Mais Alimentos (Batata Crec) está instalada está instalada desde 2007. Com a lei de incentivo fiscal, a empresa passou a se beneficiar emabrilde 2010, sendo imediatos os resultados como a ampliação das vendas e consequentemente o aumento do quadro dos colaboradores passando de 19 para 80 , dos quais 60 colaboradores são moradores de Vassouras. O parque Industrial conta ainda com as empresas Estruaço, HJ Construtora e HM Máster e irá receber mais duas indústrias: A Eco 4 Life, do setor de reciclagem e a WR Artefatos de Cimento. Além destas, a Okra, do grupo Wyda, de Sorocaba, 
fabricante de embalagens descartáveis, está instalada nas proximidades do parque.

A Porto Velho Cerâmica chegou ao município antes da redução do ICMS. Está sediada no distrito de Andrade Pinto. Em Ipiranga, a obra de construção do distrito industrial abarcará a Metalúrgica Cosmetal S.A. e a Siderúrgica Pires do Rio.

\section{Estatísticas do Cadastro Central de Empresas}

Segundo informações do IBGE (2011), Vassouras conta com 717 empresas, que empregam 7.253 pessoas com salário médio entorno de 2 salários mínimos. Através da Tabela 3 percebe-se, que no período de
2006 a 2009, houve diminuição do número de unidades locais, bem como no valor médio de salários mensais e no número de empresas atuantes. De 2007 para 2008 houve um aumento de 81 unidades, porém em 2009 houve decréscimo de 120 unidades.

Se considerarmos que o município tem aproximadamente 34.410 habitantes, dos quais 22.000 estão em idade economicamente ativa, é estarrecedor o quadro que se apresenta, já que diante das informações geradas pelo IBGE, em 2009 haviam 7.253 pessoas ocupadas. Devemos considerar ainda que a Universidade Severino Sombra e a Prefeitura Municipal de Vassouras empregam juntas aproximadamente 2.600 pessoas.

Tabela 3. Estatística do Cadastro Central de Empresas

\begin{tabular}{|ccccc}
\hline ANO & $\mathbf{2 0 0 9}$ & $\mathbf{2 0 0 8}$ & $\mathbf{2 0 0 7}$ & $\mathbf{2 0 0 6}$ \\
\hline Número de Unidades Locais & $\mathbf{7 1 7}$ & 837 & 756 & $\mathbf{7 2 9}$ \\
\hline Pessoal Ocupado Total & 7.253 & 6.276 & 6.861 & 6.576 \\
\hline Pessoal Ocupado Assalariado & 6.320 & 5.314 & 5.889 & 5.663 \\
\hline Salários e outras remunerações & 87.448 & 67.715 & 69.961 & 63.707 \\
Salário Médio Mensal & 2 & 3 & 3 & 3 \\
\hline Números de Empresas Atuantes & 703 & 817 & Não Informado & Não Informado \\
\hline
\end{tabular}

Fonte. IBGE, Cadastro Central de Empresas 2009. Rio de Janeiro IBGE: 2011- Adaptado pela autora

\section{Estudo de uma Realidade Regional - Vassouras}

A Contabilidade Gerencial é um importante instrumento de apoio aos micro e pequenos empreendimentos, no que tange as questões de âmbito gerencial. O reconhecimento de sua utilidade e efetiva aplicação dentro do quadro de gestão dos negócios pode ser associado ao próprio sucesso ou insucesso dos empreendimentos. A Contabilidade Gerencial apresenta-se como uma ferramenta eficaz de auxílio ao controle interno, propiciando a ampliação do processo informacional que visa contribuir nas tomadas de decisões bem como alocação de recursos referentes aos investimentos e lucros. Diante do exposto justifica-se o estudo da Contabilidade Gerencial e sua utilização por parte dos empreendedores.

Para tal, é necessário realizar incursões sobre a realidade dos negócios locais e verificar a relação com esta importante ferramenta gerencial. Pretendemos responder as seguintes questões: Será que os empreendedores conhecem e fazem uso das ferramentas gerenciais propiciadas pela Contabilidade Gerencial, ou será que estão restritos, em suas relações com seus contadores apenas a atenderem as exigências fiscais? Será que a experiência acumulada e continuada no ramo dos negócios deu maior estofo aos empreendedores antigos no que toca a esta possibilidade de ferramenta de gestão? Será que os novos empreendedores, contam com esta ferramenta? Será que os empreendedores estão satisfeitos com os serviços de contabilidade de que são clientes?

Para este fim, elegeu-se o Município de Vassouras, para o desenvolvimento de pesquisa exploratória. De acordo com Beuren (2003, p.80), a caracterização da pesquisa exploratória:

[...] ocorre quando há pouco conhecimento sobre a temática a ser abordada. Por meio do estudo exploratório, busca-se conhecer com maior profundidade o assunto, de modo a torná-lo mais claro ou construir questões importantes para a condução da pesquisa.

Ressalta Gil apud Beuren (2003, p.80) que:

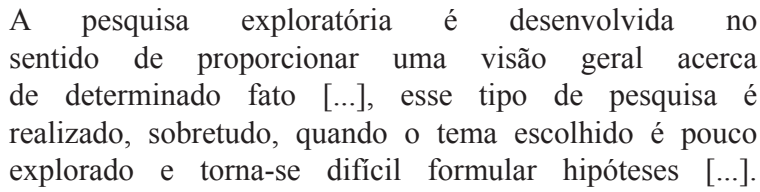

Nossa escolha pelo município de Vassouras como lócus de análise, parte também desta perspectiva. Embora a maior parcela territorial do município seja composta por empreendimentos rurais, a participação deste ramo dos negócios no PIB local é muito pequena. 
O maior percentual do PIB está centrado no setor terciário da economia, como apontado anteriormente. Para este estudo, reconhecemos a importância dos micro e pequenos empreendimentos no seu papel de dinamizador das economias locais. Mesmo nos grandes polos concentradores das atividades industriais, etambém concentradores das maiores frações da população, ainda ali, o papel das MPEs são de fundamental importância. Nas cidades de pequeno porte, seu papel é fundamental na geração de postos de trabalho, ou seja, na produção de emprego e renda. Este quadro dinamizador da economia é de fundamental importância social.

Para o município de Vassouras, essa realidade não é diferente. Apesar de ser a sede da Fundação Educacional Severino Sombra (FUSVE) - mantenedora da Universidade Severino Sombra (USS) -, a maior geradora de empregos da região Centro Sul Fluminense (com aproximadamente 1300 postos de trabalho), é no conjunto de MPEs que a maior parcela da população encontra postos de ocupação, ainda que estes empreendimentos guardem relação direta ou indireta em seus ramos negociais com a FUSVE.

Para fins deste estudo, optou-se por verticalizar a coleta e análise de dados sobre o mundo dos negócios na zona central da sede do município. A área conhecida como "centro da cidade" é bem demarcada por ruas que concentram uma importante parcela dos empreendimentos locais. São os bares e restaurantes situados na fração da Avenida Expedicionário Oswaldo de Almeida Ramos, que ficou conhecida como Broadway e diversos seguimentos de negócios, a exemplo de papelarias, estabelecimentos de vestuários, padarias, lojas de ferragens, farmácias, etc., na Rua Caetano Furquim.

É neste conjunto central que se encontra a chamada Rodoviária Velha, lugar de onde parte e para onde convergem todas as linhas de ônibus que integram o município sede a seus bairros e distritos. Também é nessa zona central que a própria FUSVE concentra a maior parte de suas atividades. É no conjunto de prédios da antiga linha férrea que estão situados a presidência da instituição e suas unidades administrativas. É onde se encontra também o principal Campus da Universidade Severino Sombra, situado na Broadway.

É ainda nesta parte central que se localiza o

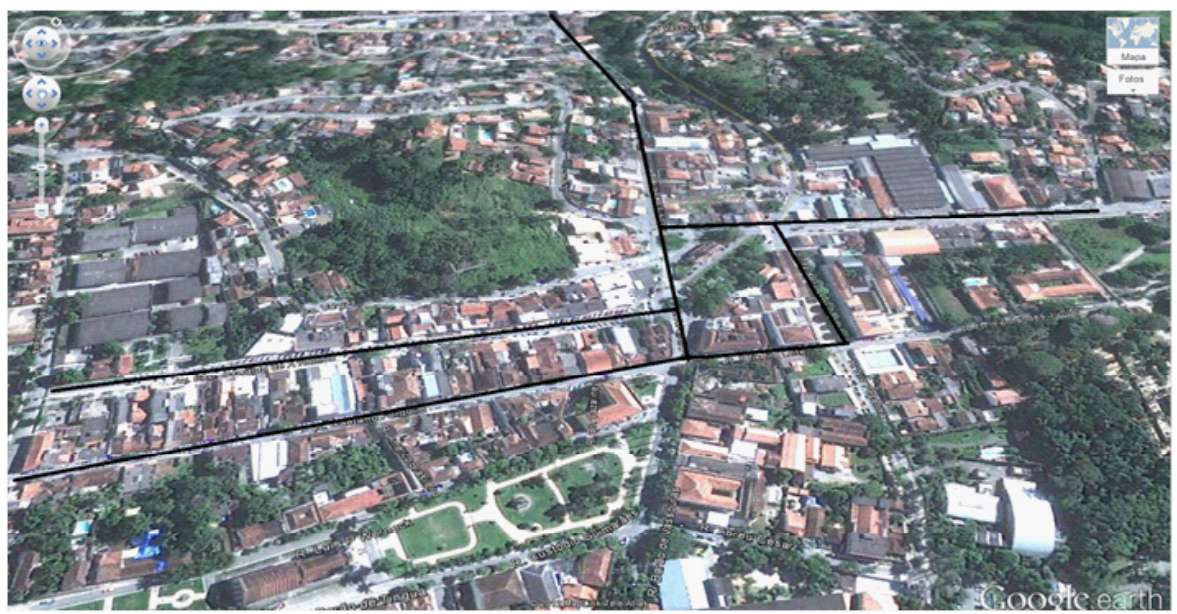

Figura 1. Ruas pesquisadas.

Fonte: Google Earth (2012)

SENAI, uma das maiores referências nacionais em tecnologia de alimentos e uma das mais respeitadas Cervejaria Escola de toda a América Latina. Ainda na região central se situam a maioria dos estabelecimentos de ensino da Educação Básica da localidade, a exemplo os colégios Sul Fluminense de Aplicação, Colégio dos Santos Anjos, Colégio Estadual Ministro Raul Fernandes, Instituto de Educação Thiago Costa, Centro de Educação e Crescimento Tia Conceição e Centro de Educação e Crescimento Arco-íris.

Encontram-se ainda as instituições de representação política do município. O Centro da Cidadania, concentra várias das instituições de serviço público, a exemplo do DETRAN e da repartição do Ministério do Trabalho e Emprego. É ainda no Centro da Cidadania que está situada a Prefeitura Municipal e a maioria de suas secretarias. As secretarias não alocadas no Centro da Cidadania estão espraiadas nas imediações da zona central da cidade, a exemplo das secretarias de Saúde e de Cultura.

É ainda nesta zona central, que se situam todos os estabelecimentos financeiros do lugar. Banco do Brasil, Caixa Econômica Federal, Bradesco, Itaú, além de postos de crédito como o BMG. Lá também estão as Casas Lotéricas e o posto dos Correios. Na zona central ou em suas imediações ainda estão a Delegacia de Polícia, o Fórum e os cartórios de registro de títulos e documentos.

Na parte central da cidade, estão situados um posto de saúde da família e a Policlínica Municipal. Em suas imediações existem dois hospitais. A grande maioria das farmácias estão situadas na zona central. Além de 
lá se situarem grande parte dos consultórios médicos e dentários particulares. Também é neste espaço que se localizam a maioria dos escritórios de advocacia, as imobiliárias e os escritórios de contabilidade.

Este espaço central é o mesmo que ainda em início do século XIX se configurou como nucleação urbana do lugar. Ao longo daquele século, foi edificado um conjunto patrimonial importante por seu valor histórico. A Igreja Matriz de Nossa Senhora da Conceição, a Praça Barão de Campo Belo, o Solar Barão de Itambé, o Solar Barão do Ribeirão, o Solar Barão de Massambará, a Praça Maurício de Lacerda, o Cemitério, a Casa de Cultura, O Museu Casa da Hera, a Casa de Câmara e Cadeia, são parte de um significativo e imponente conjunto arquitetônico, que promove afluxo de visitantes e potencializa as atividades turísticas do lugar. É ainda na zona central ou em suas imediações que estão a maioria dos hotéis e pousadas do lugar, a exemplo do Mara Palace Hotel, da Pousada Colina Verde, da Pousada Vale das Palmeiras, do Hotel Gramado da Serra, do Parque Hotel Santa Amália, etc.

É, portanto, para este espaço que se dirigem a maioria dos habitantes do lugar, em suas atividades cotidianas e rotineiras e para onde seguem a maioria dos turistas e a grande maioria dos estudantes. Dito de outro modo, este é o espaço onde ocorre a maioria dos negócios do município.

Para fins desta pesquisa, percorreu-se um total de 109 estabelecimentos situados à fração da Av. Expedicionário Oswaldo de Almeida Ramos conhecida como Broadway, a Rua Caetano Furquim, a Rua Joaquim Teixeira Leite, a Rua Irmã Maria Agostinho (Rodoviária Velha), a Avenida Otávio Gomes, Rua Velho de Avelar, Rua Dr. Domingos de Almeida, e a Praça Martinho Nóbrega. Todas estas ruas estão localizadas na zona central da cidade conforme apresentado na Figura 1. Este número é muito significativo, visto que abarca a grande maioria dos estabelecimentos de micro e pequeno porte situados nesta imediação e representa mais de $10 \%$ de todos os negócios estabelecidos no município, independente de seu porte. Segundo dados do IBGE (2011) eram 703 empresas atuantes em 2009.

Alcançar o volume de 109 estabelecimentos pesquisados no intervalo de um mês foi tarefa que exigiu alto grau de disciplina e comprometimento. Tão importante quanto à coleta é a tarefa de sistematizar os dados e transformá-los em substrato importante para sua transformação em conhecimento.

Existe claro entendimento sobre a escolha do tema. Compreende-se que o estudo pode contribuir no conhecimento sobre a sustentabilidade dos empreendimentos. Daí deriva a importância de tamanho esforço na coleta de dados e sua análise, que, pelo material coletado, não será esgotado neste trabalho. As informações colhidas permitirão ainda a continuidade de estudos futuros. A amostra de 109 micro e pequenos empreendimentos localizados no Município de Vassouras decorre da importância desse segmento no desenvolvimento do município através da geração de empregos e renda.

Considera-se para os fins desta pesquisa, o universo amostral de 100 estabelecimentos, pois 9 recusaram-se a contribuir com nosso estudo. Embora tal recusa também expresse uma forma de comunicação que não deve ser desprezada, observou-se que a grande maioria dos proprietários ou gestores dos estabelecimentos desprenderam tempo e esforço para contribuir com o estudo.

Como já apresentado acima, Vassouras é município situado na Região Centro Sul Fluminense do Estado do Rio de Janeiro, e tem grande parte de sua vida econômica regida pelo setor terciário da economia. Para fins deste estudo, optou-se por verticalizar a coleta e análise de dados sobre o mundo dos negócios na zona central da sede do município. Participaram da pesquisa 100 (cem) empresas, sendo 79 (setenta e nove) microempresas e 21(vinte e uma) empresas de pequeno porte, todas atuam no ramo comercial e de prestação de serviços como demonstra o Quadro 1:

Quadro 1. Número de Empresas por Porte e Atividade Exercida

\begin{tabular}{|c|c|c|}
\cline { 2 - 3 } \multicolumn{1}{c|}{} & \multicolumn{2}{c|}{$\begin{array}{c}\text { Número de Empresas por } \\
\text { Atividade Exercida }\end{array}$} \\
\hline Porte da Empresa & Comercial & $\begin{array}{c}\text { Prestação de } \\
\text { Serviços }\end{array}$ \\
\hline Microempresa & 72 & 07 \\
\hline $\begin{array}{c}\text { Empresa de Pequeno } \\
\text { Porte }\end{array}$ & 19 & 02 \\
\hline
\end{tabular}

Fonte. Questionários aplicados.

A pesquisa também verificou os anos de existência desses negócios. Conhecer a idade das empresas é importante. No que toca a esta questão, Dolabela, ao tratar do plano de negócios, é enfático ao afirmar que por falta de planejamento e conhecimento gerencial, são elevados os indicadores de mortalidade de empresas em seus anos iniciais (CREPALDI, 2008). Diferente da hipótese levantada, quando da elaboração do projeto de pesquisas, os dados apontam à existência de negócios duradouros em Vassouras. Constatou-se que 63\% das empresas que participaram da pesquisa tem 6 (seis) ou mais anos de existência. Contudo, deve-se destacar que sobre estes dados, é necessário parcimônia e cautela. Como já apontado anteriormente, entre os anos de 2008 e 2009 existiu forte retração no número de estabelecimentos. Eram 807 empreendimentos atuantes em 2008, contra 703 em 2009, o que aponta uma retração de 104 empresas. Contudo, para este estudo, não se realizou investigação sobre as motivações de encerramento ou suspensão de atividades destes negócios. Ao tratarmos dos negócios vivos, observa-se que $37 \%$ dos estabelecimentos investigados estão na 
Tabela 4. Faixa Etária das Empresas Pesquisadas

\begin{tabular}{cc}
\hline 0 á 5 & 37 \\
6 á 10 & 22 \\
11 á 20 & 20 \\
21 ou + anos & 21 \\
\hline
\end{tabular}

Fonte. Questionários Aplicados.

faixa etária de 0 a 5 anos.

Entre os negócios investigados percebeu-se grande variação etária. Nos extremos, encontramos o negócio mais jovem com apenas 8 meses de funcionamento. Já no extremo oposto, observou-se estabelecimentos com até 51 anos de existência. Esta pluralidade aponta importantes indícios sobre os negócios no lugar. Além da existência de um grande percentual de negócios plenamente estabelecidos, a se considerar a longa duração, observa-se a existência de negócios jovens. Esses dados indicam existir motivação em se abrir novos empreendimentos no lugar.

Através da análise apresentada a seguir, verificouse que a maioria dos empreendedores afirmou conhecer a Contabilidade Gerencial(62\%), enquanto 38\% afirmaram não conhecer. Porém ainda se verifica que parte desses empreendedores, $43 \%$, utiliza a Contabilidade somente para fins fiscais contra $57 \%$ que utilizam para fins gerenciais e fiscais. Os dados, em parte contraditórios, indicam que alguns destes respondentes, não conhecem a Contabilidade Gerencial, ou ao menos desprezam sua importância para a tomada de decisão e auxilio no processo de gestão, o que acarreta a diferença de 5\% entre as resposta sobre o conhecimento e a utilização da Contabilidade Gerencial como ferramenta importante. Por outro lado, apresenta-se aqui certa tradição cultural sobre este ramo da ciência da gestão. A relação entre os MPEs e os escritórios de contabilidade, muitas vezes são centrados em atividades fiscais e trabalhistas.

Percebe-se que esse é um problema recorrente dentro das empresas, já que vivemos em um país com elevada carga tributária. Mas, é necessário observar que a Contabilidade Gerencial inclui o planejamento tributário. É papel de todo administrador ou gestor maximizar as riquezas e minimizar as perdas. $\mathrm{O}$ planejamento tributário é um instrumento indispensável no controle interno dos negócios. $\mathrm{O}$ administrador antes do fato gerador pode utilizar métodos legais para minorar o peso da carga tributária, o que permite minimizar o impacto tributário nos gastos das empresas. Porém, ao fazê-lo, deve sempre respeitar o ordenamento jurídico. É isso que se constitui na chamada elisão fiscal.

Entretanto os empreendedores apenas se preocupam com as obrigações fiscais e assessórias, cumprindo somente com o que a legislação estabelece devido ao excesso de obrigações e burocracias, utilizando os relatórios contábeis para a prestação de contas com o Fisco. Atendo-se as obrigações tributárias, não percebem a Contabilidade Gerencial como um instrumento de suporte a administração e gestão dos negócios. Conforme ressalta Chér (1991, p.36) "A contabilidade tem sido encarada como um instrumento tão somente para se atender a uma série de exigências legais e burocráticas, e não encarada como um instrumento de apoio à administração".

Em nosso questionário, solicitamos aos respondentes que atribuíssem um grau a seus conhecimentos sobre a Contabilidade Gerencial. Para tal, estabeleceram-se três níveis: MUITO; POUCO; NENHUM. Trata-se de uma questão reflexiva. Nela, os Administradores/Gerentes teriam como parâmetros suas próprias percepções e saciedade sobre o tema. As respostas são resultados da reflexão e análise que o próprio respondente tem sobre seu conhecimento. Observa-se, contudo, que não se trata de avaliar se os mesmos dominam ou não dominam os conceitos pertinentes a Contabilidade Gerencial. Apenas se acreditam dominá-los e em que grau.

Gráfico 4. Grau de conhecimento de Administradores/Gerentes em Contabilidade Gerencial

\section{Grau de conhecimento de Administradores/Gerentes em Contabilidade Gerencial}

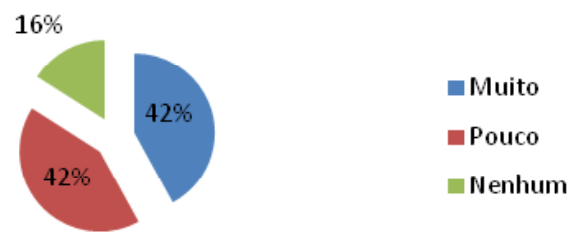

Fonte. Questionários Aplicados.

No universo investigado, um empate, $42 \%$ dos respondentes afirmaram conhecer bastante sobre o tema. Já, outros $42 \%$ também afirmaram conhecer, mas desta vez, pouco. Os outros 16\% afirmaram desconhecer esta ferramenta. Os dados são sugestivos, e indicam que existe subutilização das potencialidades da Contabilidade Gerencial no mundo dos negócios do município de Vassouras. Lembremo-nos que 57\% dos respondentes afirmaram fazer uso da Contabilidade para fins fiscais e gerenciais. Se somarmos os valores daqueles que afirmaram pouco ou nada conhecer sobre as possibilidades da Contabilidade Gerencial como ferramenta importante, observaremos o total de $58 \%$ dos respondentes. Se realizarmos outro cálculo aritmético para tentar compreender o que estes dados podem indicar, chegaremos ao seguinte resultado: do total de $57 \%$ dos respondentes que afirmaram fazer uso da Contabilidade para fins gerenciais e fiscais, apenas $42 \%$ afirmaram conhecer bem a ferramenta que utilizam. Logo, $15 \%$ dos respondentes utilizam mal, ou subutilizam esta ferramenta. Como os dados tratam 
da percepção e saciedade que os próprios respondentes têm de seu conhecimento, há que se considerar que estes devem, ou deveriam ter ciência de que necessitam de maior conhecimento para uma melhor gestão de seus negócios.

Contribui para esta análise, a noção que a Contabilidade Gerencial tem como objetivo primordial fundamentar as decisões do Administrador que através do processo informacional torna o processo decisório mais garantido e coeso e gera instrumentos eficazes na administração de recursos através do planejamento.

Segundo Longenecker²:

[...] os administradores precisam ter informações precisas, significativas e oportunas, se quiserem tomar boas decisões. Isso é particularmente verdadeiro quando se refere à necessidade de informações financeiras sobre as operações da empresa. A experiência sugere que a falta de aptidão em sistemas contábeis é um fator básico de insucesso entre pequenas empresas.

Ressalta-se que questões como essa, que tratam da negligência ao uso das ferramentas de gerenciamento, têm contribuído negativamente para a sustentabilidade dos negócios. As falhas gerenciais consistem em um dos fatores principais para a mortalidade das Micro e Pequenas Empresas.

Visando melhor delinear a percepção dos empreendedores locais sobre suas estratégias de gestão e as ferramentas que adotam para este fim, procurou-se verificar a utilização dos relatórios contábeis no auxilio ao processo decisório. Observa-se que os relatórios se constituem em um conjunto organizado de informações colhidas pela contabilidade e retratam a situação patrimonial da empresa e as mutações ocorridas durante o exercício. Contêm a saúde financeira da empresa, e suas informações podem, e devem apoiar o processo decisório. Verificou-se que $61 \%$ do nosso universo amostral afirmam utilizar os relatórios contábeis para auxiliar no processo decisório. Outros $36 \%$ disseram não fazer uso e $3 \%$ dos entrevistados optaram por não responder a esta questão.

Gráfico 5. Utilização dos Relatórios no Processo Decisório.

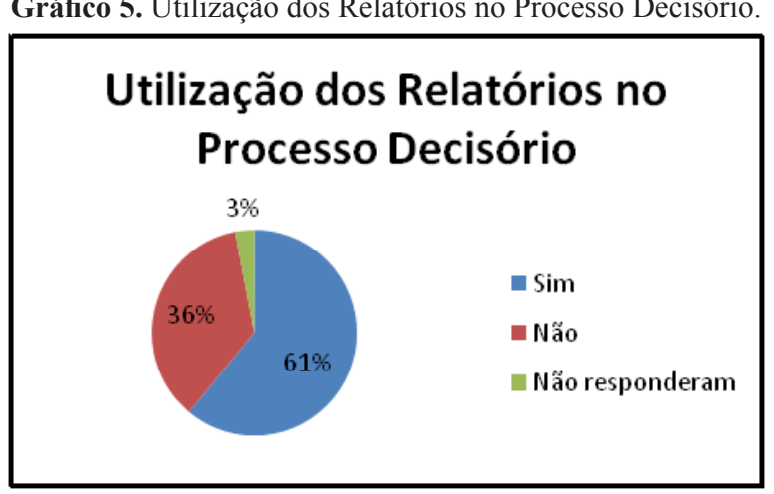

Fonte. Questionários Aplicados

Os dados apresentados na compilação desta

2 Cf. LONGENECKER, J. G.; MOORE, C. W.; PETTY, J. W. Administração de pequenas empresas. São Paulo: Makron Books, 1997. Pag. 515 . resposta, se colacionados àqueles que tratam do conhecimento da Contabilidade Gerencial são muito próximos. Foram $62 \%$ dos respondentes que afirmaram conhecer a Contabilidade Gerencial, contra 61\% daqueles que afirmaram fazer uso dos relatórios contábeis no processo decisório. Os dados seriam bastante correlatos. Seriam, mas não são. Levemos em conta que embora os $61 \%$ dos respondentes tenham afirmado fazer uso dos relatórios para fins decisórios, apenas $57 \%$ afirmaram fazer uso da Contabilidade Gerencial na gestão da empresa. Os dados indicam que uma parcela destes respondentes não considera que os relatórios contábeis são parte dos instrumentos da Contabilidade Gerencial. Se relacionarmos estes dados com o grau de conhecimento que os gestores reconhecem ter, ou não, recorde-se que apenas $42 \%$ afirmaram conhecer bem a Contabilidade Gerencial. Estes dados sugerem que pelo menos $19 \%$ dos que afirmam fazer uso dos relatórios como instrumento de tomada de decisão o faz com pouca segurança e conhecimento.

Descartados os 3\% que optaram por não responder a este quesito, pode-se verificar que $36 \%$ responderam não fazer uso dos relatórios contábeis. Este percentual também se aproxima daquele conjunto de 38 respondentes que afirmaram não conhecer a Contabilidade Gerencial. Mas são inferiores àqueles $43 \%$ que utilizam a contabilidade somente para fins fiscais. Se considerarmos que $16 \%$ afirmaram nada conhecer, ou ainda que $42 \%$ afirmaram conhecer pouco, o número percentual daqueles que informaram não fazer uso dos relatórios contábeis para fins de tomada de decisão, é discrepantee intensa, que se reflete e assevera outro ponto de nossa pesquisa. Buscamos informações sobre a compreensão dos relatórios fornecidos pelo contador. A grande maioria dos respondentes afirmou compreender totalizando $80 \%$ contra $19 \%$ que afirmaram ter dificuldades na compreensão e $1 \%$ que optou por não responder a este quesito.

Gráfico 6. Dificuldades em compreender os Relatórios fornecidos pelo Contador.

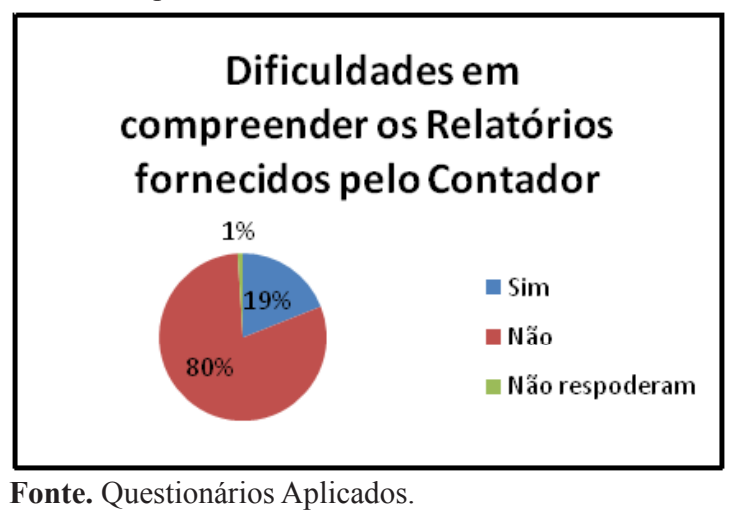

Apesar de a maioria afirmar não possuir dificuldades de compreensão dos relatórios, ainda existe um número significativo de empresas que não os compreendem. Os indicadores entre aqueles 
que afirmaram ter dificuldades em compreender os relatórios contábeis $(19 \%)$ são muito próximos daqueles que afirmaram não conhecer a Contabilidade Gerencial (16\%). Se somarmos os números dos que afirmaram conhecer pouco ou muito a Contabilidade Gerencial (84\%), e compará-los aos percentuais dos que afirmam não terem dificuldades em compreender os relatórios contábeis $(80 \%)$, novamente, encontramos certa simetria das informações. Observe-se que de $16 \%$ a $19 \%$ dos respondentes deixam aparente seu total desconhecimento sobre aspectos contábeis que envolvem diretamente a gestão de seus negócios. Estes números são elevados e demonstram a urgência de formação de habilidades e competências gerenciais, sob pena da própria insustentabilidade de seus negócios.

Outro dado é alarmante. A coligação entre os percentuais encontrados dos que afirmaram conhecer (muito ou pouco) a Contabilidade Gerencial, e aqueles que afirmaram compreender os relatórios contábeis, embora guardem proximidade, expressam um dado preocupante. Se 43\% dos respondentes afirmaram fazer uso da Contabilidade apenas para fins fiscais, isso indica que mais de $50 \%$ dos que afirmaram compreender os relatórios contábeis, não o compreendem como instrumento para tomada de decisão. Se os cálculos aritméticos permitem a construção de indicativos para análises - e acreditamos que sim - se realizarmos a subtração dos índices percentuais entre os que afirmaram compreender os relatórios contábeis $(80 \%)$ daqueles que afirmaram fazer uso da Contabilidade apenas para fins fiscais (43\%) chegaremos ao indicador de $37 \%$ dos respondentes como conhecedores das possibilidades dos relatórios como ferramenta de gestão. Este número é inferior aos $42 \%$ que afirmaram conhecer bem a Contabilidade Gerencial.

Estes dados, embora discrepantes, não são inconsistentes. Por um lado, existe uma cultura tributarista no uso dos serviços de Contabilidade, o que minimizam seus potenciais usos gerenciais. Por outro, os relatórios contábeis são incapazes de promover efetiva comunicação para seus dados. Mais que instrumentos de circulação de dados, os relatórios devem ser corretamente compreendidos como instrumentos de comunicação. Compreende-se portanto, que os relatórios devam ser de fácil explanação para que os usuários possam fazer uso e não complicados e indecifráveis. À medida que o administrador necessita de elementos adequados para consubstanciar a tomada de decisão, a análise de tais informações permitem, por exemplo, a adoção de medidas corretivas que tomadas em tempo hábil, evitam a insolvência do estabelecimento.

Os relatórios contábeis são ferramentas importantes para os empreendedores no auxilio do processo decisório, pois são equivalentes às informações colhidas pela Contabilidade e retratam a situação patrimonial da empresa e as mutações ocorridas durante o exercício. Essas informações podem respaldar o processo decisório e por outro lado é fundamental a saúde financeira da empresa à medida que o administrador necessita de elementos adequados para consubstanciar a tomada de decisão e, havendo necessidade de implantar medidas corretivas essas informações permitirão inserilas em tempo hábil.

A negligência pode acarretar severas penalidades e descontinuidades nas empresas, como não programar mudanças que sejam necessárias à sua sustentabilidade, por ausência de conhecimento apurado ou mesmo por não saber a sua real situação financeira. Mas ao considerar a existência de negócios duradouros em Vassouras, estes dados mostram que empresas podem até sobreviver sem um controle adequado das finanças ou quem sabe um controle inconsistente. Contudo, sobreviver é diferente de realizar uma boa gestão administrativa, e tornar os negócios rentáveis. Lembremos, como apresentado anteriormente, que a função da efetiva administração dos negócios reside no maximizar as riquezas e minorar as perdas.

Como pergunta final de nosso questionário fechado, estava aquela que avaliava o grau de satisfação dos gestores, como clientes dos serviços prestados pelos contadores. Para este questionamento, 3\% dos respondentes preferiram não apresentar sua avaliação. Outros 8\% afirmaram não estarem satisfeitos. Mas a grande maioria, 89\%, afirmaram estar satisfeitos com os serviços prestados.

Conforme salientado anteriormente, as respostas fornecidas pelos Administradores/Gerentes tiveram como parâmetro principal seu próprio grau de percepção e saciedade sobre os conhecimentos que acreditam ter sobre a temática da Contabilidade Gerencial. A resposta a este último quesito é indicativo importante sobre o grau de exigência dos gestores como clientes, bem como o papel que esperam ser cumprido pelos profissionais de contabilidade. O grau de exigência é proporcional ao grau de conhecimento. Ao passo que estes profissionais cumprem seus papéis tributaristas e por vezes trabalhistas, os clientes, em sua grande maioria, ficam satisfeitos.

Lembremo-nos da advertência de Iudícibus (1998, p 286) aos profissionais de contabilidade, tratando a importância da comunicação que deve ter os relatórios contábeis:

[...] lembre-se que nem todos falam a sua linguagem (a contábil) com a perfeição que você faz. Alguns apenas balbuciam, outros pensam que falam, e não sabem nada. Todos eles [...] merecem entender em sua plenitude os relatórios emanados da Contabilidade.

A conjunção das respostas apresentadas pelos respondentes, principalmente quando se busca sua validade na coligação com outras respostas, demonstram que embora apenas $42 \%$ dos respondentes tenham 
afirmado conhecer bem a Contabilidade Gerencial, talvez nem este montante tenha realmente os conhecimentos mínimos necessários a fazerem o melhor uso dos Relatórios Contábeis para fins gerenciais. Estes dados se tornaram aparente quando realizamos a subtração entre os índices percentuais dos que afirmaram compreender os relatórios contábeis daqueles que afirmaram conhecer pouco a Contabilidade Gerencial. Entender a plenitude dos relatórios pressupõe ultrapassar a barreira de seus fins fiscais.

Contudo, o contador, não é tratado como um parceiro da gestão financeira e estratégica do empreendimento. Sobre ele, repousa o papel de calculador de impostos e tributos, juntador de notas fiscais, escriturário de livros contábeis. Às suas funções são agregados o papel de intermediário entre a empresa e o Estado. A produção de relatórios, obrigatórios por lei (entre eles o Balanço Patrimonial e o Demonstrativo de resultados do Exercício), são encarados como ferramentas tributárias, mas não como ferramentas de gestão.

O elevado grau de satisfação sobre os serviços contábeis expressam o despreparo dos gestores, os reflexos da tradição sociocultural em que estão imersos e as tensões cotidianas que recebem do Estado com suas elevadas taxas tributárias. Não reflete a possibilidade de agregação do papel estratégico e maximizador de riquezas, que pode ter as ciências contábeis. O desprezo cultural a estas possibilidades bloqueia grande parte dos empreendedores locais da ampliação de sua capacidade de gestão.

\section{Considerações Finais}

Ao longo do presente trabalho compreendemos a importância da Contabilidade Gerencial na vida econômica das empresas e o desafio da mesma em contribuir para o aperfeiçoamento e ampliação do campo de atuação no ambiente empresarial. Em uma economia cada vez mais competitiva e dinâmica que têm contribuído para as constantes mudanças na gestão, uma vez que os recursos disponíveis são escassos, é necessário e fundamental escolher entre as melhores alternativas, visando, sobretudo informações objetivas e relevantes ao processo decisório.

Ressalta-se a relevância na administração dos recursos financeiros dentro da empresa, de modo que os empreendedores devem geri-los ativamente, objetivando a saúde financeira da empresa. Portanto esta ferramenta permite a ampliação do controle sistêmico das finanças da empresa. Deste modo, o empresário poderá relacionar os custos diretos com os indiretos e calcular o preço de seus produtos ou serviços compatibilizando com o mercado, mas, levando em conta estratégias para crescer sem se endividar. Uma boa administração, permite realizar relação entre as dívidas da empresa e os ativos. Proporciona calcular que o tempo de pagamento dos seus clientes não seja maior do que o tempo médio que suas dívidas serão cobradas. Apoia a redução de custos desnecessários, promovendo a correta alocação dos recursos financeiros da empresa.

Verificou-se que as informações abrangidas pela Contabilidade Gerencial não devem ser somente compreendidas para fins tributários, prática essa ainda muito utilizada pelos empresários, mas, sobretudo, no auxilio ao processo decisório e de gestão.

O estudo ainda evidenciou a importância das Micro e Pequenas Empresas no cenário econômico brasileiro, pela contribuição significativa na geração de empregos e renda. As MPEs ocupam papel de destaque promovendo o desenvolvimento da interiorização de modo a ampliar as oportunidades e responsáveis por dinamizar as economias locais, tendo função socioeconômica essencial para o país.

A escolha do Município de Vassouras como lócus de análise se mostrou relevante, pois verificou-se que sua economia é em grande medida dinamizada pelos micro e pequenos empreendimentos, que em conjunto, contribuem para a maior parcela de geração de empregos e renda. Contudo, apesar do relevo que as Micro e Pequenas Empresas têm para a economia do Município, concluiu-se que existe a necessidade de aperfeiçoamento de seus instrumentos de gestão. Apesar da existência de empreendimentos duradouros, foi possível verificar que as ferramentas de gestão adotadas são insuficientes para cumprir o papel de maximização das riquezas.

Podendo ser apurado através das respostas oferecidas pelos Administradores/Gerentes a nossa pesquisa, o confronto dos índices demonstrou que embora $80 \%$ dos respondentes afirmaram compreender os relatórios contábeis, apenas $57 \%$ destes informaram fazer uso da Contabilidade para fins gerenciais o que denota a permanência de tradição cultural tributarista e não gerencial. A observação desses dados permitiu concluir que no Município de Vassouras existe subutilização dos recursos contábeis para fins de gestão administrativa, estando diretamente relacionado ao fato de acreditarem ter conhecimento sobre a Contabilidade Gerencial (84\%, se somados os que afirmaram conhecer bem e pouco).

A outra associação se deu no grau de satisfação com os serviços contábeis prestados, observando-se que $89 \%$ dos respondentes afirmaram estar satisfeitos! Identificou-se que a ausência de conhecimento torna o cliente menos exigente, afinal, não é possível mensurar o que não conhecemos. É, portanto, necessário aprimorar as habilidades e competências gerenciais. A implantação da Contabilidade Gerencial não significa a criação de novas ferramentas, mas a melhoria da qualidade da relação entre contadores e administradores. Trata-se de aspecto relacionado aos instrumentos de comunicação 
e a agregação de valor ao conjunto informacional, elemento fundamental a construção de conhecimento do negócio.

Confirmou-se que a Contabilidade Gerencial praticada no âmbito empresarial venha garantir a continuidade da empresa de forma sustentável, somado a essa característica contribui para o país já que os micros e pequenos empreendimentos potencializam a função socioeconômica. Aliado a isso se percebe o efeito multiplicador e transformador, que pode mudar a história dos empreendimentos maximizando as riquezas e garantindo geração de empregos e renda.

\section{Referências}

ALVES, Giovanni - Dimensões da Globalização: o capital e suas contradições. $2^{\text {a }}$ ed. São Paulo: Praxis, 2001.

ANDRADE, Maria Margarida de. Como preparar trabalhos para cursos de pós-graduação: noções práticas. $5^{\mathrm{a}}$ ed. São Paulo: Atlas, 2002

ANTHONY A. ATKINSON, RAJIV D. BANKER, ROBERT S. KAPLAN, S. MARK YOUNG - Contabilidade Gerencial. $2^{\text {a }}$ ed. Atlas, 2008

ANTUNES, Maria Thereza Pompa. Capital Intelectual. São Paulo: Atlas, 2000

ARRUDA, Mauro. A inserção de produtos no mercado. Revista SEBRAE, Brasília, n. 6, p. 69-73, set./out. 2002.

AZEVEDO. João H. Como Iniciar uma Empresa de Sucesso. Rio de Janeiro: Qualitymark, 1992

BARROS, Frederico Robalinho de. Pequena e média empresa e política econômica: Um desafio à mudança. Rio de Janeiro: Apec, 1978.

BES, Fernando de Trías. O livro negro do empreendedor - Tradução Luís Carlos Cabral - 2 ${ }^{\text {a }}$ Ed - Rio de Janeiro: BestSeller, 2010.

BEUREN, Ilse Maria. Como elaborar trabalhos monográficos em contabilidade: teoria e prática. São Paulo: Atlas, 2003.

BRASIL. Lei Complementar $n^{\circ} 127$, de 14 de agosto de 2007. Altera a Lei Complementar $n^{\circ} 123$, de 14 de dezembro de 2006. Brasília, 14 de agosto de 2007; 186 o da Independência e 119 o da República. D.O.U. de 15.8.2007.

CASSARRO, Antonio C. Sistema de Informações para Tomada de Decisões. São Paulo: Pioneira, 1998.

CATELli, Armando. Controladoria: uma Abordagem da Gestão Econômica. São Paulo: Atlas, 1999

CARVALHO, José Ribamar Marques de. Medição de desempenho empresarial: um estudo nas organizações do setor salineiro no estado do Rio Grande do Norte. Dissertação (Mestrado em Ciências Contábeis) Programa Multiinstitucional e Inter-regional da UnB, UFPB, UFPE e UFRG, Natal, 2007.

CHÉR, Rogério. A gerencia das pequenas e médias empresas: o que saber para administrá-las, 2ed. rev. e ampl. São Paulo: Maltese, 1991.

CHIAVENATO, Idalberto. Introdução à teoria geral da administração. 4ed. São Paulo: Makron Books, 2000.

CREPAlDI, Silvio Aparecido. Teoria e Prática da Contabilidade Gerencial. $2^{\text {a }}$ ed. Atlas, 2008.

DOLABELA, Fernando. O segredo de Luísa. Uma ideia, uma paixão e um plano de negócios: como nasce o empreendedor e se cria uma empresa. São Paulo: Cultura, 1999

FRANCO, Hilário. Contabilidade Geral. 23º ed. São Paulo: Atlas, 1997.

GUTIERREZ, Gustavo Luís. Gestão Comunicativa: maximizando criatividade e produtividade. Rio de Janeiro: Qualitymark, 1999.

IUDICIBUS, Sergio de. Contabilidade Gerencial. 6 ed. São Paulo: Atlas, 1998.

KOTLER, Philip; KELLER, Kevin Lane. Administração de marketing. $12^{\circ}$ ed. São Paulo: Pearson Prentice Hall, 2006.

LIMA, E. O, 2001. As Definições de Micro, Pequena e Média Empresas Brasileiras como Base para Formulação de Políticas Públicas.Anais do II Encontro de Estudos Sobre Empreendedorismo e Gestão de Pequenas Empresas - EGEPE, 2001.

LONGENECKER, J. G.; MOORE, C. W.; PETTY, J. W. Administração de pequenas empresas. São Paulo: Makron Books, 1997.

LORIGGIO, Antonio.De onde vêm os problemas: Métodos para um diagnóstico eficaz - São Paulo: Negócio, 2002.

LIEBER, Renato Rocha.Teoria de Sistemas. Guaratinguetá: UNESP, s/d

MARION, José Carlos. Contabilidade empresarial. $8^{\text {a }}$ ed. São Paulo: Atlas, 1998.

MARION, José Carlos. Contabilidade empresarial. 12a ed. São Paulo: Atlas, 2006.

MARTINS, Rosilda Baron. Metodologia científica: como tornar mais agradável a elaboração de trabalhos acadêmicos. Curitiba: Juruá, 2005.

Moritz, Gilberto de Oliveira. Processo decisório. Florianópolis: SEAD/ UFSC, 2006

PEREIRA, M. J. L. B.; FONSECA, J. G. M. Faces da Decisão: As Mudanças de Paradigmas e o Poder da Decisão. São Paulo: Makron Books, 1997.

QUEIROZ, Valéria Márcia. Sociologia da sociologia da exclusão. Sociedade e Cultura. Goiânia, v. 5, n. 4, p. 193-198. 2002

SANTOS (S.), FREITAS (H.) e LUCIANO (E.M.). Dificuldades para o uso da Tecnologia da Informação. RAE na web, São Paulo, 2004.

SEBRAE e DIEESE - Anuário do trabalho na micro e pequena empresa: 2010-2011. 4. Ed. / Serviço Brasileiro de Apoio às Micro e Pequenas Empresas (Org.); Departamento Intersindical de Estatística e Estudos Socioeconômicos [responsável pela elaboração da pesquisa, dos textos, tabelas e gráficos]. -Brasília, DF; DIEESE, 2011.

SEBRAE. In ESTUDOS e pesquisas. Fatores Condicionantes e Taxa de Mortalidade de Empresas no Brasil. Brasília, 2004.

SEBRAE - Serviço Brasileiro de Apoio à Micro e Pequena Empresa e Fundação Nacional. Aprendendo a empreender. Sem ficha catalográfica. P. 13.

SIMON, Herbert A. A capacidade de decisão e liderança. Rio de Janeiro: Fundo de Cultura, 1963.

SOUZA, Diocésar C.; KÜHL, Marcos R.; PACHECO, Vicente. Avaliação do desempenho: um estudo entre as maiores empresas do sul do Brasil. In. Anais eletrônicos do XIV CONGRESSO BRASILEIRO DE CUSTOS. João Pessoa, PB, 2007.

SPÍNOLA, A. S; Os Pequenos Negócios, a Informalidade e suas Perspectivas. Revista SEBRAE, 2007.

TRIGO, Luís Gonzaga Godoi. A sociedade pós-industrial e o profissional em turismo. Campinas, SP: Papirus, 1998.

Internet:

BISPO, Carlos Alberto Ferreira. CAZARINI, Edson Walmir. A evolução do processo decisório.

Disponível em: http://www.abepro.org.br/biblioteca/ENEGEP1998 ART094.pdfAcesso em 23 de janeiro de 2012 às $22 \mathrm{~h} 48 \mathrm{~min}$.

IBGE CIDADES - Disponível em: <http://www.ibge.gov.br>Acesso em 15 de março de 2012 às $14 \mathrm{~h} 33 \mathrm{~min}$.

Indicador Serasa Experian de Falências e Recuperações, Xeyla Oliveira (2010) -Número de falências de microempresas é o menor desde 2005 Disponível em: < http://www.agenciasebrae.com.br>Acesso em 16 de abril de 2012 